\title{
ABSTRACTING AND EXTRACTING: CAUSAL COHERENCE AND THE DEVELOPMENT OF THE LIFE STORY
}

\author{
By Azriel Grysman
}

\author{
A Thesis Submitted to the \\ Graduate School - New Brunswick \\ Rutgers, The State University of New Jersey \\ in partial fulfillment of the requirements \\ For the degree of \\ Master of Science
}

Graduate Program in Psychology

Written under the direction of

Professor Judith A. Hudson

And approved by

New Brunswick, New Jersey

October, 2009 


\title{
ABSTRACT OF THE THESIS
}

Abstracting and Extracting: Causal Coherence and the Development of the Life Story

\author{
By AZRIEL GRYSMAN
}

Thesis Director:

Judith A. Hudson

This study compared episodic memories of emerging adults (age 18-22) and early adolescents (age 13-15) for life story events and other memories, in an attempt to distinguish characteristics of the life story. Participants were also asked to describe the connection between the stories told. Stories were analyzed for three measures of causal coherence: 1) meaning making, 2) narrative complexity, and 3) the use of causal terms; and one measure of thematic coherence. Results show an impact of age in three measures (meaning making, narrative complexity, and thematic coherence) and of story type (life story vs. non-life story) in all measures. Effects of age show that young adults' narratives showed more evidence of self-related abstract thinking and the ability to see multiple dimensions. Effects of story type indicated that turning point narratives and event connections narratives contained more self-related lessons and insights, displayed greater recognition of complexity, and employed more causal terms. Descriptions of peak experiences and low points did not differ significantly from other episodic memories on 
these measures of coherence. As well, connections between narratives were more abstract and self-related in the older group and in the life story condition. Findings show that two important narrative characteristics, narrative complexity and reference to self-related lessons and insights develop in adolescence, and are more prevalent in turning point narratives. 


\section{Acknowledgement}

I would like to thank Judith Hudson for her constant guidance and support, both for guiding the methods of this project and for always being there to discuss the theoretical questions that drive this research. I would also like to thank Jeanette HavilandJones and Dan Ogilvie for their helpful input. Finally, I am grateful to Paola Ricardo, Melody Wilding, and Jackie Santiago for their tireless work with subjects and coding data with me.

This thesis is dedicated to Gavi, whose love and support sustains me through good and bad, and who pushes me to be a better researcher and a better person. 


\section{Table of Contents}

Abstract ii

Acknowledgement iv

Causal Coherence and the Development of the Life Story 1

Method 11

$\begin{array}{ll}\text { Results } & 14\end{array}$

$\begin{array}{ll}\text { Discussion } & 19\end{array}$

$\begin{array}{ll}\text { References } & 24\end{array}$

Tables 1-5 29

Figures 1-4 35

Appendix A: Instructions to Participants 39

Appendix B: Sample Narratives 41 


\section{List of tables}

Table 1: Causal Terms Used

Table 2: Narrative Complexity Scale

Table 3: Meaning Making Scale

Table 4: Thematic Coherence Scale

Table 5: Correlations Between Measures 


\section{List of Illustrations}

Figure 1: Causal Terms Results

Figure 2: Narrative Complexity Results

Figure 3: Meaning Making Results

Figure 4: Thematic Coherence Results 
Abstracting and Extracting: Causal Coherence and the Development of the Life Story

The study of autobiographic memory examines memories for specific events that have occurred in a person's lifetime. Beginning in adolescence, individuals put these memories together to tell a narrative about themselves and this narrative is known as the life story (McAdams, 1985). According to Erikson (1968), when young adolescents begin the process of identity formation, they reflect upon their memories and attempt to define a self that has maintained consistency throughout their experiences. When reflecting upon life as a whole, individuals have a desire to see unity (Linde, 1993) and purpose in their lives (McAdams, 1985) and to establish a sense of continuity and understanding of the self (Habermas \& Bluck, 2000). Individuals construct a narrative - the life story - that attempts to demonstrate a consistent self, despite changes that have occurred.

According to McAdams (1985), from the time of adolescence, people "notice incongruities between themselves in the present and past." Coping with such inconsistencies can be a difficult challenge, particularly when trying to establish an identity. Narrative creates meaning out of isolated events by identifying the events as contributing parts to a greater whole; thus it serves an explanatory function for one's current status. It has been suggested that this narrative helps the individual predict future behavior based on the story it tells of the present (Boyer, 2005, Polkinghorne, 1988). Thus, life story memories differ from other autobiographic memories in that they strive to establish coherence across various memories.

Habermas and Bluck (2000) write that the establishment of global coherence in particular, i.e. establishing connections between singular episodes and the broader 
narrative, distinguishes life story memories from other memories, because these memories integrate the narrative told with the sense of self. They defined four characteristics of the life story; temporal coherence refers to the ability to locate memories in a temporal order, including the use of calendars or landmark events as reference points; cultural concept of biography is the ability to form a framework that can be used to organize memories into a narrative. These first two elements appear by early adolescence due to cognitive development. Causal coherence and thematic coherence are later developments that are linked to the cognitive changes occurring in late adolescence.

Causal coherence refers to the effort by an individual to link different actions and episodes to his personality and development. Actions are connected to life stages and to each other, changes are explained, and a general sense of continuity of the self is formed (Habermas \& Bluck, 2000). Linde (1993) explains that "establishing causality" in the life story is a useful means of arriving at a sense of continuity, and that people are driven to justify events in their lives that don't fit in to a causal framework. Causal coherence is a process of interpretation in which the individual continually attempts to make meaningful connections between life events and the sense of self (Linde, 1993, McAdams, 2001, Pals, 2006). Pals (2006) stresses that the attempt for coherence is an ever-changing process in which the individual creates meaning from experiences. The life story is an "active creation" of the individual (Habermas \& Bluck, 2000), one that is constantly being re-created in response to new situations and new discoveries (Bruner, 2002). New connections are constantly being uncovered and new meanings created. 
One way to measure causal coherence is to analyze the usage of terms or phrases that make causal connections (referred to as causal terms). Habermas and de Silveira (2008) asked students, age 8-20, to pinpoint important events in their lives and speak about them. The resulting monologues were measured for indicators of causal coherence by coding for causally related propositions about extended events or personality and for biographical arguments (e.g. statements that explain events in terms of past experiences or developmental level). Habermas and de Silveira (2008) showed a significant developmental increase in causally related propositions between all four age groups $(8$, 12,16 , and 20 years) and in biographical arguments between 12-year-olds and 16-yearolds. This is the first developmental evidence of causal coherence directly from life stories. Statements involving causal propositions and statements that link events to personality or biography indicate an effort by the individual to create a causal framework between different memories by linking behaviors to stable information. While this study showed the increase of causal statements through development, it did not compare the use of causal terms in life story monologues to other types of autobiographic memories, and focused on qualitative statements as opposed to coding for specific causal terms. In an analysis of personal histories from Holocaust survivors, Barclay (1996) showed that stories demonstrating more coherence display a higher frequency of "causal-conditional" terms (e.g. because, since, then). A story that has less "local" causal coherence is harder to understand upon reflection about its meaning, and may be a contributing factor to the stress that arises from traumatic memories. The presence of more causal terms may be an indicator of greater effort or ability to establish causality in memory, and the first step towards establishing global coherence in a narrative. 
A second approach to analyzing the causal coherence of narratives is analyzing the complexity expressed within them. The goal of causal coherence in the life story is to unite different events or aspects of the self into a seamless whole. This unity can be easier achieved if the individual has multiple avenues of meaning from which to draw. Narrative complexity analyzes the degree to which a narrative identifies multiple perspectives, dimensions, or emotions in a story. It was first introduced by Suedfeld, Tetlock, and Streufert, (1992) and used in coding political rhetoric in an attempt to measure differentiation and integration of thought. In a previous study (McAdams, Bauer, Sakaeda, Anyidoho, Machado, Magrino-Failla, White, \& Pals, 2006), scores on measures of narrative complexity were correlated within individuals over time and increased with development. In this study, college students described ten key autobiographic memories by answering questions from the Guided Autobiography (a questionnaire constructed to elicit life story memories, McAdams, 1997), and repeated the process three months later and again three years later. However, because this and other studies (McAdams, Anyidoho, Brown, Huang, Kaplan, \& Machado, 2004, McAdams et al., 2006) relied solely on the Guided Autobiography, which contains very explicit prompt for life story memories, and did not compare this data to other types of memories, we cannot conclude from their work if narrative complexity is a feature of the life story per se or simply a feature of narrative style that changes with development.

Narratives that display complexity have potential for integration. The goal of the life story is to integrate the episodes of one's life into a stable identity (McAdams, 2001), and the ability to see multiple dimensions provides more opportunity for ways to integrate. Examining the development of narrative complexity is important because 
narrative complexity may be a precursor to the construction of a coherent life story. If narrative complexity is more present in life stories than in other memories that would identify narrative complexity as a structural element of the life story reflecting more effortful construction. Furthermore, as the claim of many theorists is that the life story is a phenomenon that emerges in adolescence, narrative complexity may be an indicator of integrative ability not achieved before this developmental milestone.

A third approach to measuring causal coherence was introduced by McLean (2005), who measured meaning making. Individuals look for meaning when they reflect on the implications of a particular event (McLean \& Thorne, 2003), and this reflection can be expressed in different forms. McLean and Thorne distinguish between lessons and insights. Lessons refer to knowledge gained regarding a specific situation that can direct future behavior in that realm; insights refer to meaning that is gained from an experience and is applied more broadly to other areas of one's life. These lessons and insights integrate episodes from a person's life into a broader context, leading to a sense of why they occurred or how one led to another. McLean and Thorne (2003) refer to the emergence of a more abstract meaning making as one symptom of adolescent abstract thinking. They hypothesized, in accordance with McAdams' work on life stories (1988), that the quality of lessons reported would become more reflective and have broader applications as adolescents mature. However, McLean and Thorne's concept of meaning making does not distinguish between lessons and insights learned about general topics and those learned about the self. Furthermore, these studies track development from age sixteen, but do not examine causal coherence from earlier in adolescence. 
Thematic Coherence, the fourth characteristic of the life story identified by Habermas and Bluck (2000), refers to the ability to interpret and summarize multiple episodes along thematic lines. Although pre-adolescent children can identify themes in single stories (van den Broek, Lorch, \& Thurlow, 1996), the ability to integrate multiple episodes of one's own life involves “active interpretation” (Habermas \& Bluck, 2000) that goes beyond the effort for single stories. Through their growing abilities for abstract reasoning, adolescents learn tools of inference and interpretation and gain the ability to view the personal past from multiple angles, especially as their ability to see multiple perspectives grows. With the development of thematic coherence, individuals are able to group multiple episodes in their lives to gain further insight into the self. The ability for thematic coherence has been linked to higher ego development, cognitive effort, and reporting connections about personal growth (McLean \& Fournier, 2008).

It is important to note the similarity between thematic and causal coherence. Both refer to processes that unify varied experiences and create a causal framework within memory. Methods for studying thematic coherence include examining statements and hedges (phrases where the narrator indicates awareness of interpreting the event) within larger stories (Habermas \& de Silveira, 2008), or coding the presence or absence of a theme in self-defining memories (McLean \& Fournier, 2008), but these methods rely on participants spontaneously discussing theme, as opposed to directly being prompted for it.

While previous research (e.g. Habermas \& de Silveira, 2008) has examined defining coherence and monitoring its development over time, there has not been a direct comparison of life story memories to other autobiographic memories. Such a comparison 
is important because it distinguishes global coherence as a stable feature of the life story and not simply a feature of adult autobiographic memory.

Most discussions about the life story begin by recognizing Erikson's (1968) identity formation stage, but the construction of autobiographic memories begins much earlier. Developmental research on the story format of autobiographic memory begins as early as children can speak, and by age 3 children can reliably relate narratives about regularly occurring events in the course of a conversation (Fivush \& Haden, 1997). Several investigations (e.g. Hudson, 1991, Reese, Haden, \& Fivush, 1993, Tessler \& Nelson, 1994) have shown that mother-child conversations teach children how to talk about and organize memories; schemas and scripts are created, and children as early as the preschool years use the story structure to relate events (Nelson \& Fivush, 2004). Autobiographic memory researchers view children's growing ability to relate memories as a dynamic interaction between memory abilities and social learning which teaches children how to structure the details of their memories. Throughout development, children are taught what features of a story matter, and memories that follow a certain story structure are encouraged. This structure is then applied to future events as they become memories and affects the way the developing child stores memories of events as they occur.

The story structure for autobiographic memories is not the only factor that impacts on how events are remembered. Conway and Pleydell-Pearce (2000) introduced the term working self, to refer to the ways in which the self impacts how incoming information is encoded. When memories are first encoded, the encoding process occurs in relation to goals of the self (Howe \& Courage, 1993). Thus, more vivid memories often 
confirm or oppose motives of the self (Conway \& Pleydell-Pearce, 2000). The model proposed here views the life story as the confluence of the story schema and the self schema. The life story is where the connection between self and memory becomes explicit, where individuals form an identity through memories of past events, selecting those that are most "self-defining" (Singer \& Salovey, 1993) to understand themselves (McAdams, 2001), and crafting a story from those memories to create a narrative representation of the self.

With the onset of adolescence, children are able to reason in the abstract and to think more about the self. These developments have been attributed to the capacity for hypothetical reasoning consistent with Piaget's stage of formal operational thought as well as Erikson's stage of concern about identity (Habermas \& Bluck, 2000). The result of the cognitive advances occurring in this time period is a greater desire to reflect upon meaning and purpose in one's own life. The life story thus develops as a result of this desire for a causal framework in which to understand multiple episodes of one's life.

Although it is widely agreed that the life story is an adolescent development, only one study to date (Habermas \& de Silveira, 2008) has demonstrated direct evidence from a population younger than age 16 . Their study indicated developmental increases during adolescence on two measures of causal coherence, namely biographical arguments and causally related statements of long duration. It is crucial to compare adults and early adolescents to properly understand the differences between the life story and the autobiographic memories that precede it in childhood. 
The current study examined the defining features of the life story and its development in adolescence in order to identify elements of structure in the life story that differ from other memories.

Past research has shown evidence of increases along numerous indicators of causal coherence over the course of development, but the standard by which a story is defined as a life story is unclear. Methods have ranged from asking participants for a selfdefining memory (e.g. McLean \& Fournier, 2008), asking students to give a monologue of their life narrative (Habermas \& de Silveira, 2008), or by prompting them with different questions of life story-relevant memories in the Guided Autobiography (McAdams et al., 2006). The current study used segmented stories to attempt to capture trends of the life story. Three stories were chosen from McAdams' Guided Autobiography (1997), the peak experience (high point), the nadir experience (low point), and the turning point experience. These stories were compared to stories in which participants were not given guidelines beyond being asked to relate memories of events that occurred within one year of the three life story events, respectively. Comparing life story episodes to each other and to other memories provides the opportunity to examine whether different types of life story memories serve different functions, and when they differ from other memories in reliable, measurable ways. While Habermas and Bluck (2000) stress the importance of global coherence, a macrostructure that acts as a life story schema, the goal of this study was to see if the building blocks of that structure can be identified in the single stories that create the life story.

For the purposes of studying thematic coherence, previous studies have shown an increase in thematic coherence from age 8 to 12 years as indicated by explanations of 
statements and hedges within a larger story (Habermas \& de Silveira, 2008), and the presence of statements relating to theme (McLean, 2005). This study employed a more direct way of analyzing thematic coherence by asking participants for themes connecting previous stories they had told. This approach can be viewed as analyzing the causal coherence of thematic statements.

Another goal of this investigation was to compare life story and autobiographical memory narratives of early adolescents and emerging adults. We examined different types of narratives across age groups to understand how those of emerging adults (age 18-21) differ from those of early adolescents (age 13-15).

Finally, we analyzed the role of the self in determining narrative coherence. Previous work on life stories focused on the development of causal and thematic coherence within narratives, but has not related that coherence to a sense of self. Because the life story is understood as the narrative that defines identity (McAdams, 2001), coding methods were developed for this investigation to examine references to the self when measuring meaning making and thematic coherence. Thus, while McLean's distinction between lessons and insights is maintained in this study, we distinguished between lessons and insights gained about the self and those gained about other ideas or people in the narrative.

The central hypothesis of this study was that older participants would be more likely to incorporate insights into their narratives than younger participants, and would more often relate lessons and insights to a concept of self. As these two elements, attributing more abstract meaning and relating events to the self, are crucial elements of 
the life story and of narrative identity, we also expected to see more of them in life story memories than in non-life story memories.

Method

\section{Participants}

This study included 102 participants from two age groups. The older group of emerging adults consisted of 56 college students ( 25 female) from Rutgers University recruited through the psychology department's research participation website. Ages ranged from 18 to 22 years $(\mathrm{M}=18.77, \mathrm{SD}=.83)$, although the majority $(91 \%)$ of subjects were 18-19 years. Self-reported ethnicity was: Caucasian $(n=20)$, Asian $(n=18)$, Indian $(n=9)$, Black $(n=2)$, Hispanic $(n=2)$, and Other $(n=4)$. One participant did not report ethnicity.

The younger adolescent sample consisted of 46 high-school students (21 female) recruited from a private high school in Riverdale, NY, and by independent advertising in Toronto, Ontario, Canada. Ages ranged from 13 to 15 years $(\mathrm{M}=14.08$, $\mathrm{SD}=.72)$. Selfreported ethnicity was: White $(n=44)$, and Other $(n=2)$.

\section{Procedure}

Participants typed a total of six memory narratives into a computer. Three narratives were reports of "life story" memories; specifically, participants were asked to report a "high point" memory, a "low point" memory, and a "turning point" memory. The questions shown to the participants were adapted from McAdams' Guided Autobiography (1997). The high point questions asked participants to describe an episode in which they experienced something extremely positive. The low point asked for an episode in which participants experienced something extremely negative. The turning point asked for an 
episode in which participants experienced a time of change or transition. The three "non life story" narratives were accounts of memories from a similar time frame (within one year) that need not relate to the "life story" memories they followed. Seven minutes were given to describe each of the six memories, and the order was fully counterbalanced. After writing each set of memories (life story and non-life story), participants were asked to describe, in four and a half minutes, any connections between the three life story memories, and any connections between the three other memories.

\section{Coding}

Narratives were coded using three scales to assess causal coherence (causal terms, narrative complexity, and meaning making), and one scale to assess thematic coherence.

\section{Causal Terms.}

Use of causal terms (e.g. because, since, therefore) indicates an effort by the individual to create a causal framework between different memories by linking behaviors to stable information, and is especially relevant when linking information to traits or personality. Use of fifteen causal terms were coded, as shown in Table 1. The frequency of word occurrence was obtained using Linguistic Inquiry and Word Count (LIWC 2007) software (Pennebaker, Booth, \& Francis, 2007) which reports the frequency of occurrence of categories of words in narrative units.

\section{Narrative Complexity Scale.}

Narrative complexity analyzes the recognition of multiple dimensions, perspectives or emotions in a narrative. This measure used an adaptation of Suedfeld et al.'s (1992) conceptual/integrative complexity scoring procedure. Different adaptations 
have been employed by McAdams et al. $(2004,2006)$ in the past. Here, using a 1-3 scale, with a score of 3 indicating recognition of multiple perspectives, dimensions, or emotions, and a score of 1 indicating no such recognition. The middle score, 2, was coded when multiple dimensions, perspectives, or emotions are identified but not elaborated on. Examples of this scale can be found in Table 2. Two independent coders rated $25 \%$ of the narratives with agreement rates of $r=.78(r=.79$ for emerging adults, $r$ $=.76$ for early adolescents). One coder finished coding the remainder of the data. Past studies have shown that narrative complexity scores increase with age (McAdams et al., 2006).

Meaning Making Scale.

A meaning making scale was developed that was derived from McLean (2005). Meaning making refers to the tendency of participants to describe lessons or insights that they gained connected to the story they told. It reflects an effort by the individual to fit the story into a broader framework by analyzing how the narrative is relevant beyond its specific details. Lessons refer to knowledge gained regarding a specific situation that can direct future behavior in similar situations; insights refer to meaning that is applied more broadly to other areas of one's life and reflects a more abstract approach to a memory. This distinction reflects how broadly people analyze the narratives they tell. Because we proposed that the sense of self is a critical element of the life story, we adapted McLean's scheme to include a distinction between general lessons and insights and lessons and insights related to the self (see Table 3 for examples). The coding scheme for meaning making used a 0-4 scale, where zero indicates no lesson reported. Codes of 1 and 2 were assigned to lessons and codes of 3 and 4 were assigned 
to insights. In each pair the higher code ( 2 and 4 ) was used when there was a reference to the self and the lower code (1 and 3) was used when there was no reference to the self. Statements that were self-referential received higher scores because these statements are viewed as exhibiting greater effort to connect a narrative to the life story. Two independent coders rated $25 \%$ of the narratives with agreement rates of $r=.86(r=.83$ for emerging adults, $r=.88$ for early adolescents). One coder finished coding the remainder of the data.

\section{Thematic Coherence.}

Thematic coherence refers to the ability to interpret and summarize multiple episodes along thematic lines. This coding scheme analyzed the final two narratives, the ones in which participants were asked to write about connections between the previous narratives. It examined the basis used for comparison on a 0-5 scale, with the lower ends of the scale including statements that there is no connection or connections based on time, and the higher ends of the scale including statements of what the participant learned from the events or how they impacted or reflected the participant's personality. A full description of coding categories for thematic coherence can be seen in Table 4. Two independent coders rated $25 \%$ of the narratives with agreement rates of $r=.87(r=.83$ for emerging adults, $r=.92$ for early adolescents). One coder finished coding the remainder of the data.

\section{Results}

Three measures of causal coherence (meaning making, narrative complexity, and causal terms) were analyzed to compare narrative coherence across types of narrative and across age groups. 


\section{Use of Causal Terms}

A 2 (Age Group; Adolescents and Adults) x 2 (Narrative Type; Life Story and Non-Life Story) x 4 (Story Condition; High point, Low point, Turning point, Event connections) repeated measures analysis of variance (ANOVA) was performed to examine use of causal terms in the narratives. This analysis revealed a main effect of story condition, $F(3,297)=32.28, p<.001$, but no main effect of age group, $F(1,95)<1$. The main effect of story condition was qualified by a significant story condition by age group interaction effect, $F(3,285)=8.06, p<.001$. These data are shown in Figure 1 . There was a marginally significant main effect of narrative type, $F(1,99)=3.06, p=.08$.

To understand the story condition by age group interaction, $t$-tests were computed for all pair-wise comparisons (high point, low point, turning point, event connections across both age groups). Results indicated that in the event connections condition, younger participants used more causal terms than the older participants, $t(100)=2.32, p$ $<.05$, whereas there were no significant age differences for any of the other story conditions.

\section{Narrative Complexity}

Higher scores on the narrative complexity scale indicated greater recognition of multiple perspectives, dimensions, or emotions in the narrative. Again, higher scores were expected for the older group and for life story memories. A 2 (Age Group) x 2 (Narrative Type) X 4 (Story Condition) repeated measures ANOVA revealed a significant main effect of age group, $F(1,99),=13.06, p<.001$, with the emerging adult group scoring higher $(M=2.33, S D=.81)$ than the early adolescent group $(M=2.05, S D$ $=.93)$, and a main effect of story condition, $F(3,198)=9.52, p<.01$. The main effect of 
story condition was moderated by a significant narrative type by story condition interaction effect, $F(3,198)=8.35, p<.001$. These data are displayed in Figure 2 . Unexpectedly, there was no main effect of narrative type $(F(1,99)<1)$.

In understanding the story condition by narrative type interaction, $t$-tests were computed for all pair-wise comparisons (high point, low point, turning point, event connections) across both the LS and NLS narratives. As predicted, scores in the Life Story (LS) condition were significantly higher than in the Non-Life Story (NLS) condition for turning point narratives, $t(99)=2.92, p<.01$, and for the event connections narrative, $t(99)=3.17, p<.01$. However there was no significant difference between the LS and NLS conditions on the low point narratives. Surprisingly, the NLS condition scored significantly higher than the LS condition on the high point narrative, $t(101)=$ $2.60, p<.05$.

\section{Meaning Making}

The meaning making scale measured use of lessons and insights, as well as references to the self. Higher scores were expected for the older group and for life story memories, because in the life story people attempt to connect multiple experiences to the sense of self, and this is generally viewed as an adolescent development. Scores on this scale revealed a degree of skewness ranging from -.05 to $3.02, S E=.237$. The skewed nature of this data was expected, as participants were not explicitly instructed to report lessons and insights. Furthermore, previous work (McLean, 2005, McLean and Thorne, 2003, Thorne, McLean, and Lawrence, 2004) found lessons or insights in only $20 \%$ to $30 \%$ of single memories reported by young adults, so many zero values were expected and, indeed, found. However, an ANOVA was performed, as previous studies have 
shown that " $F$-values are robustly insensitive to moderately skewed distributions" (Lindquist, 1953, Peselow, Sanfilipo, Fieve, and Gulbenkian, 1994).

A 2 (Age Group) x 2 (Narrative Type) X 4 (Story Condition) repeated measures ANOVA found a significant main effect of age group, $F(1,99),=21.46, \mathrm{p}<.001$, where the emerging adult group $(M=1.05, S D=1.25)$ scored higher than the early adolescent group $(M=.57, S D=1.03)$. The ANOVA also revealed significant main effects of narrative type, $F(1,99)=77.28, p<.001$, and of story condition, $F(3,297)=30.30, p<$ .001 , and a significant narrative type by story condition interaction, $F(3,297)=19.91, p$ $<.001$. These data are displayed in Figure 3 . $^{1}$

In understanding the story condition by narrative type interaction, $t$-tests were computed for all pair-wise comparisons (high point, low point, turning point, event connections, for both LS and NLS narratives). As predicted, scores on the turning point narratives were significantly higher in the LS condition than in the NLS condition, $t(99)$ $=10.05, p<.01$. As well, event connections narrative scores were significantly higher in the LS condition than in the NLS condition, $t(99)=5.95, p<.01$. However there was no significant difference between the LS and NLS conditions on the high point or low point narratives.

\section{Thematic Coherence}

The thematic coherence scale measured the basis used for comparison between the preceding stories. Scores range from 0-5, with higher scores indicating more abstract connections between events and more use of the self in the description of theme (see

\footnotetext{
${ }^{1}$ Due to the skewed nature of the data, nonparametric tests were also conducted. Chi square tests produced the same significant main effect of age, $\chi^{2}(4, \mathrm{n}=101)=50.34, p<.01$, narrative type, $\chi^{2}(4, \mathrm{n}=101)=60.24, p<.01$, and story condition, $\chi^{2}(12, \mathrm{n}=101)=97.44, p<.01$.
} 
Table 4). It was only used for the event connections narratives, where participants were asked to describe any connections between narratives. These data are shown in Figure 4. A 2 (Age Group) x 2 (Narrative Type) repeated measures ANOVA revealed a main effect of Narrative type, $F(1,99)$, $=24.83, p<.001$, with narratives by participants in the LS condition $(M=2.74, S D=1.78)$ scoring significantly higher than participants in the NLS condition $(M=1.79, S D=1.44)$. There was no significant main effect of age group in the ANOVA, $F(1,99)=1.59, p=.21$. However, because it was predicted that the older group would score higher than the younger group, and that the LS group would score higher than the NLS group, an a priori contrast analysis was performed (see Fig. 4). This test was significant, $t(199)=4.073, p<.001$, which supported the hypothesized effects.

\section{Relationships of Scales Used}

Because the narrative complexity and meaning making scales both used qualitative judgments by the coders, Pearson's correlations were performed on all three causal coherence scales to test the interrelationships. Because all three of these measures are used to study one theoretical construct, some overlap was expected, but because they are measuring different elements of coherence, that overlap was expected to be minimal. Pearson's correlations between the three scales were computed for each overlapping narrative (high point, low point, turning point, event connections for both LS and NLS narratives), for a total of eight narratives in each comparison. Correlations are displayed in Table 5.

Significant but small correlations were obtained between meaning making and narrative complexity in five of the eight comparisons. The causal terms scale did not correlate significantly with narrative complexity or with meaning making. None of the 
correlations between meaning making and narrative complexity exceeded .25 , confirming the hypothesis that these measures are somewhat related, but that each measure is independent.

\section{Discussion}

Results of this study indicated developmental differences for a number of measures relevant to the life story. Results from the causal coherence analyses indicate consistent effects of age on the meaning making and narrative complexity scales, though not on measurements of causal terms. The age effect on narrative complexity confirms the hypothesis that the ability to see multiple dimensions of a story increases with development. This finding has been demonstrated in the past (McAdams et al., 2006) with older participants, but there is now evidence involving an early adolescent population. Results on the meaning making scale show that the tendency to spontaneously draw meaning from episodes through lessons and insights also increases with age. With development these lessons and insights are perceived with greater abstraction and greater connection to the self. In contrast, there was no significant age difference in use of causal terms. This suggests that both age groups were equally competent in constructing causally organized narratives. The observed developmental differences in meaning making and narrative complexity therefore reflect more than the development of narrative competence or the acquisition of a vocabulary geared towards identifying causality, but instead indicate more qualitative changes in the development of a coherent life story.

There is widespread agreement that, while some of its elements develop earlier, the life story is an adolescent development (e.g. Habermas \& Bluck, 2000, McAdams, 
1985). The results obtained here lend insight into what enables the life story's development. With adolescence, the individual is more able to extract abstract information from concrete episodes, to pick and choose between their multiple dimensions, and use these features of the narratives to connect events to the self in a way that establishes causality between variegated life events. The abilities combine together to establish causality, enabling the individual to view his life as united around specific themes and purposes.

Results also indicated that life story memories and non-life story memories are different on several important narrative dimensions. However, this difference is mostly confined to turning point narratives and descriptions of the connections between events, narratives that required a greater effort on the part of the individual in relating one event to others. Whereas the high and low point narratives only involved telling a story, the latter two conditions required a layer of interpretation beyond the narrative, either by participants describing how or why the narrative was a turning point or by explaining how the various stories fit together. This result highlights the role that the life story plays in organizing memories. The life story is more than a collection of high points and low points, rather a reflection of how the individual organizes them, using turning points as signposts that lead the narrator along the path of life. Causal coherence is not a defining feature of every narrative in the life story. The life story creates coherence by bringing together disparate stories in the search for identity. It is the active construction undertaken by the individual that gives the life story its organizational features that differ from other memories. 
One result on the narrative complexity scale that was surprising was the significantly higher score of the non-life story condition when compared to the high point life story narrative. It is possible that stories geared towards describing a positive event require little explanation, whereas more negative stories require the narrator to work harder at understanding them. Fivush Hazzard, Sales, Sarfati, and Brown (2003) showed that children narrated negative events more coherently than positive ones, and suggested that as events become more challenging to the self, there is a greater focus on thoughts and feelings in an effort to "create coherence out of chaos" (p. 14). However, this finding was not replicated on any other scale, and so it is hard to draw any inference conclusively.

The data from turning point memories highlight the element of construction in life story memories. Pillemer (1998) stresses the constructive process of "momentous events." There are several types of such events, one of which he identifies as the turning point, that can become influential in a person's memory. The events that occur in a pivotal or turning point memory are not integrally different than other episodes in a person's life. However, once meaning has been extracted from the events, the interpretation becomes an integral part of the memory. Pillemer (1998) referred to events as commonplace as shopping in the supermarket that became pivotal in the life story because of how the individual interpreted them. According to this model, turning points present more meaning and complexity because they have undergone a process of construction that has identified their place in the sought-after causal network of autobiographical memories. 
A different approach to the relationship between self and memory is taken by Conway and Pleydell-Pearce (2000). In their self-memory system, memories are encoded with goals of the self in mind, making memories more relevant when they confirm goals of the self or starkly contrast them. According to this model, turning points do not have more construction after the fact, but are encoded in such a way that they fit an important role in the causal network of autobiographic memory.

This study does not answer whether the creation of turning points is a retrospective process, as Pillemer (1998) proposed, or if identification of an episode in the life story as relevant is something that happens during encoding, as Conway and Pleydell-Pearce's (2000) model suggests. Further research is necessary to better understand the process by which turning point memories are created. . Another question raised by these data concerns the age at which individuals are able to construct coherent life stories. Results from this investigation indicate that turning point memories are more complex, abstract, and self-related after adolescence, but there were significant differences between life story and non-life story memories of turning points even in the younger age group. Future research should focus on identifying when the process of establishing coherence is implemented in autobiographical memory, both with regards to whether it occurs during encoding or retrospectively and at what age it occurs.

There are some limitations to these results that warrant consideration. The younger population that participated was ethnically homogeneous and from a different country (Canada) than the older population (United States), but there is no a priori reason why such a difference would impact the results, especially since developmental evidence has been obtained so far from many parts of the United States, Germany, and Canada 
(Habermas \& de Silveira, 2008, McLean, 2005, McLean \& Pratt, 2006). Finally, by examining smaller, shorter narratives instead of continuous monologues (Habermas \& de Silveira, 2008), the study risks losing elements of the life story that are gained from viewing it as one cohesive unit, but gains the opportunity to analyze how certain types of narratives differ from others. This impact was seen in the interaction between story condition and narrative type. On the meaning making and narrative complexity scales, life story memories only differed significantly from non-life story memories in the turning point condition and the event connections condition. Such a result implies that the life story as a unit is greater than the sum of its parts, because the high and low point memories do not demonstrate causal coherence on their own, but are integral to the life story as a whole.

The study of global coherence is still relatively new and the scales used in this investigation need to be replicated. However, the methods used in this study to identify the narrative building blocks of a coherent narrative allow us to analyze life story narratives in terms of component features instead of viewing the life story as a singular unit. By analyzing the life story episode by episode, and by pinpointing the specific elements that contribute to coherence both in narrative structure and in self-awareness, we can track the development of coherence and examine how multiple stories are woven together to create the life story. 


\section{References}

Barclay, C.R. (1996). Autobiographical remembering: Narrative constraints on objectified selves. In D.C. Rubin (Ed.) Remembering our past: Studies in autobiographical memory. (pp.94-125). Cambridge: Cambridge University Press.

Bruner, J. (2002). Making Stories: Law, Literature, Life. New York, NY: Farrar, Straus and Giroux.

Conway, M. A., \& Pleydell-Pearce, C. W. (2000). The construction of autobiographical memories in the self-memory system. Psychological Review, 107(2), 261-288.

Erikson, E. (1968). Identity, Youth, and Crisis. New York, NY: W. W. Norton and Co.

Fivush, R., and Haden, C. (1997). Narrating and representing experience: preschoolers' developing autobiographical accounts. In P. van den Broek, P.A. Bauer, and T. Bourg (Eds.), Developmental spans in event comprehension and representation: Bridging fictional and actual events (pp.169-198). Hillsdale, NJ: Erlbaum.

Fivush, R., Hazzard, A., Sales, J.M., Sarfati, D., and Brown, T. (2003). Creating coherence out of chaos? children's narratives of emotionally positive and negative events. Applied Cognitive Psychology, 17, 1-19.

Habermas, T., \& Bluck, S. (2000). Getting a life: The emergence of the life story in adolescence. Psychological Bulletin, 126(5), 748-769. 
Habermas, T., \& de Silveira, C. (2008). The development of global coherence in life narratives across adolescence: Temporal, causal, and thematic aspects. Developmental Psychology, 44(3), 707-721.

Howe, M. L., \& Courage, M. L. (1993). On resolving the enigma of infantile amnesia. Psychological Bulletin, 113(2), 305-326.

Hudson, J.H. (1991). Learning to reminisce: A case study. Journal of Narrative and Life History, 1, 295-324.

Linde, C. (1993). Life stories: The creation of coherence. New York, NY: Oxford University Press.

Lindquist, E. F. (1953). Design and Analysis of Experiments in Psychology and Education. Oxford, England: Houghton Mifflin.

McAdams, D.P. (1985) Power, intimacy and the life story. Homewood, Illinois: The Dorsey Press.

McAdams, D.P. (1997) Guided Autobiography. Retrieved Dec. 6, 2007, from Northwestern University, Foley Center for the Study of Lives Web site: http://www.sesp.northwestern .edu/docs/guided_autobiograph.pdf

McAdams, D. P. (2001). The psychology of life stories. Review of General Psychology, $5(2), 100-122$. 
McAdams, D. P., Anyidoho, N. A., Brown, C., Huang, Y. T., Kaplan, B., \& Machado, M. A. (2004). Traits and stories: Links between dispositional and narrative features of personality. Journal of Personality, 72(4), 761-784.

McAdams, D. P., Bauer, J. J., Sakaeda, A. R., Anyidoho, N. A., Machado, M. A., Magrino-Failla, K., White, K.W., Pals, J.L. (2006). Continuity and change in the life story: A longitudinal study of autobiographical memories in emerging adulthood. Journal of Personality, 74(5), 1371-1400.

McLean, K. C. (2005). Late adolescent identity development: Narrative meaning making and memory telling. Developmental Psychology, 41(4), 683-691.

McLean, K. C., \& Fournier, M. A. (2008). The content and processes of autobiographical reasoning in narrative identity. Journal of Research in Personality, 42(3), 527-545.

McLean, K. C., \& Pratt, M.W. (2006). Life's little (and big) lessons: identity statuses and meaning-making in the turning point narratives of emerging adults. Developmental Psychology, 42, 714-722.

McLean, K. C., \& Thorne, A. (2003). Late adolescents' self-defining memories about relationships. Developmental Psychology, 39(4), 635-645.

Nelson, K., \& Fivush, R. (2004). The emergence of autobiographical memory: A social cultural developmental theory. Psychological Review, 111(2), 486-511.

Pals, J. L. (2006). Constructing the "springboard effect": Causal connections, selfmaking, and growth within the life story. In D. P. McAdams, R. Josselson \& A. 
Lieblich (Eds.), Identity and story: Creating self in narrative (pp. 175-199).

Washington, DC, US: American Psychological Association.

Pennebaker, J.W., Booth, R.J., \& Francis, M.E. (2007).Linguistic Inquiry and Word Count [Computer software]. Austin, TX: liwc.net.

Peselow, E.D., Sanfilipo, M.P., Fieve, R.R., and Gulbenkian, G. (1994). Personality traits during depression and after clinical recovery. British Journal of Psychiatry, 164, 349354.

Pillemer, D.B., (2001). Momentous events and the life story. Review of General Psychology, 5, 123-134.

Polkinghorne, D. E. (1988). Narrative Knowing and the Human Sciences. Albany, NY: State University of New York Press.

Reese, E., Haden, C. A., \& Fivush, R. (1993). Mother-child conversations about the past: Relationships of style and memory over time. Cognitive Development, 8(4), 403-430.

Singer, J. A., \& Salovey, P. (1993). The Remembered Self: Emotion and Memory in Personality. New York, NY: Free Press.

Suedfeld, P., Tetlock, P. E., \& Streufert, S. (1992). Conceptual/integrative complexity. In C. P. Smith (Ed.), Motivation and personality: Handbook of thematic content analysis (pp. 393-400). Cambridge: Cambridge University Press. 
Tessler, M., \& Nelson, K. (1994). Making memories: The influence of joint encoding on later recall by young children. Consciousness and Cognition: An International Journal, 3(3-4), 307-326.

Thorne, A., McLean, K. C., \& Lawrence, A. M. (2004). When remembering is not enough: Reflecting on self-defining memories in late adolescence. Journal of Personality, 72(3), 513-541.

van den Broek, P., Lorch, E. P., \& Thurlow, R. (1996). Children's and adults' memory for television stories: The role of causal factors, story-grammar categories, and hierarchical level. Child Development, 67(6), 3010-3028. 
Table 1

Causal terms used in analysis of word usage

Terms Used

\begin{tabular}{lll}
\hline Affect & Compel & Outcome \\
Based/basis & Consequence & Since \\
Because/ & Depend & Therefore \\
Cos/coz/cuz & Effect & Thus \\
Cause & Hence & \\
Change & How & \\
\hline
\end{tabular}


Table 2

Narrative Complexity Scale

Code Description Example

1 The author relies on a one-dimensional rule for an evaluation or making a choice, or simply doesn't make mention of multiple dimensions.

2 The author recognizes the potential for looking at something in more than one way, but does not explicate it entirely.

3 The author makes a clear specification of there being two ways to deal with something. There is a recognition that different perspectives towards something, or different dimensions of something can be held in mind at the same time.
When I was in grade eight I was so scared that I wasn't going to get into the schools that I applied to in high school, I used to go home crying to my parents saying that my school hates me and they aren't going to recommend me to the schools that I applied to which was true.

Senior year started and I was still feeling very sick all the time. Later in September, me and my girlfriend broke up, probably because I was always in a bad mood and she got tired of it.

I felt to have the radio as an outlet because I felt very much refreshed after each show. I also got the chance to do play-by-play commentary for my high school's basketball team and it is this event which led me to realize how badly I felt that I needed to be apart of the broadcasting world but at the side of sports. Not only is adrenaline being pumped through my veins at the excitement of each shot but it allows me to do what all sports lovers love to do. It lets me enjoy a sports game and lets me be a part of it to. 
Table 3

Meaning Making Scale

Code Description $\quad$ Example

$0 \quad$ No lesson is described.

I don't think that I have any "turning points" in my life that I can remember. I am sure that my view of myself changed at some point but I don't remember it.

1 A lesson is reported as We were able to experience a whole new being learned, but it does not relate at all to the narrator's sense of self

2 A lesson is reported that does pertain to the narrator's sense of self.

3 An insight is reported - a lesson that is expanded beyond the situation which is described in the memory - but it is not described as something learned about the narrator.

$4 \quad$ An insight is reported - a lesson that is expanded beyond the situation which is described in the memory - and it is described as something learned about the narrator, i.e. an insight into the self. culture, which allowed me to understand how the people around the world live differently following different cultures and values.

My high and turning points were when I experienced the most difference in my lifestyle and personality. I learned to be more responsible and independent. I felt a lot more mature and I knew I was reaching adulthood. Looking back, I felt that there are few sources of true comfort in this world, which is mainly why many join religions, but to me, guitar has provided me everything I could emotionally need.

I feel now that this was a very bad decision that I had made. It is what has limited me today. I feel as if I am where I am because of the way I set the tempo for my life that freshman year. Instead of taking control of my life and taking myself where I wanted to go, I decided to let the world around me take me with it. I did not want to be different, I did not want to succeed. I wanted to take the path of least resistance and I was happy doing that. Now I realize that that decision has left me feeling empty inside, feeling unfulfilled. I 
know that that decision was one that I will question for the rest of my life... I must live with the realization that my life is not all that it could have been. That I am not all that I could have been. 
Table 4

Thematic Coherence Scale

Code Description Example

$0 \quad$ Explicit mention of the memories not being related.

1 Topic, feature, or temporal basis for comparison is used.

2 Emotions are mentioned as a theme in common between memories.

Memories are described as one having led to or being influenced by another.

4

5
Memories reflect an impact on the self or demonstrate some characteristic.
I can't think of any resemblance between the memories. They actually differed a great bit, rather then being related. They happened within two or three years of each other.

All three of them made me feel different than I do in my average day. These events will never leave my memory because of how each of them made me feel. The low point was related to the turning point because, after the turning point my life changed completely and the high point was an effect of that... The turning point changed everything and made us kind of forget about the high points, because the low point and turning point were not so good.

Each of them made an impact on my life, and I learned something from each of them, and I will probably never forget them.

I believe that my high point, low point, and turning point and related to one another in that they established points in my life in which I endured a lot of change. When I cracked my skull, I realized that my life could have ended and it allowed me to be more motivated in conquering my goals in the future. This would eventually lead to me realizing what I wanted to do with my life which was radio and television. 
Table 5

Pearson's correlations between Meaning Making (MM), Narrative Complexity (NC), and Causal Terms

\begin{tabular}{llll}
\hline Story Condition & MM and NC & MM and Causal Terms & NC and Causal
\end{tabular}

Terms

\begin{tabular}{llll} 
High Point LS & $.22 *$ & .15 & .08 \\
High Point NLS & $.20 *$ & .12 & .10 \\
Low Point LS & .11 & .11 & .15 \\
Low Point NLS & .10 & .05 & .12 \\
Turning Point LS & $.22 *$ & .08 & .14 \\
Turning Point NLS & $.26 * *$ & -.04 & .04 \\
Event Connections LS & $.20 *$ & .04 & -.15 \\
Event Connections NLS & .12 & -.08 & .05 \\
\hline Note. All correlations reported are Pearson’s $r$ scores, and include data from the older \\
and younger participants (N = 101).
\end{tabular}




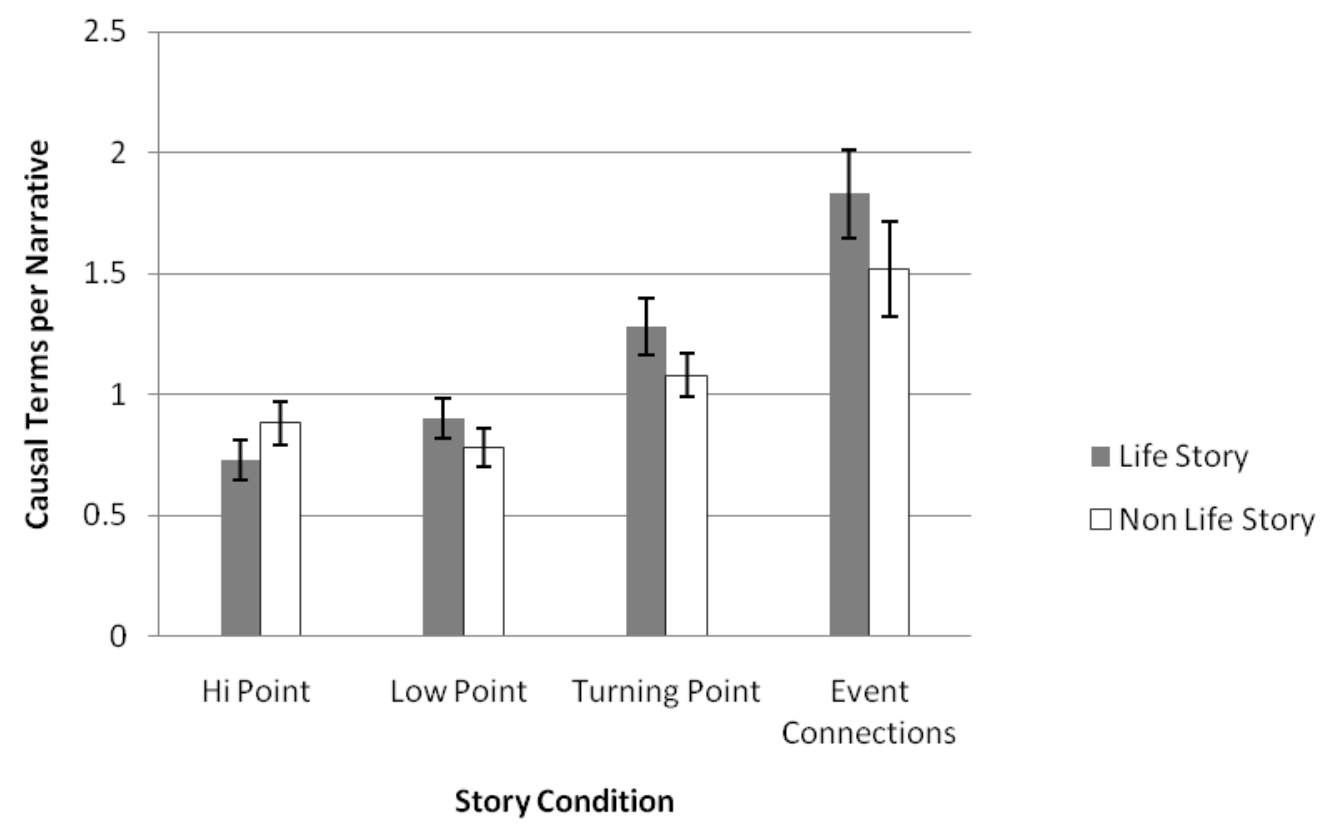

Figure 1. Mean causal term usage by narrative condition (Life Story and Non-Life Story) and story condition. Error bars represent standard errors. 


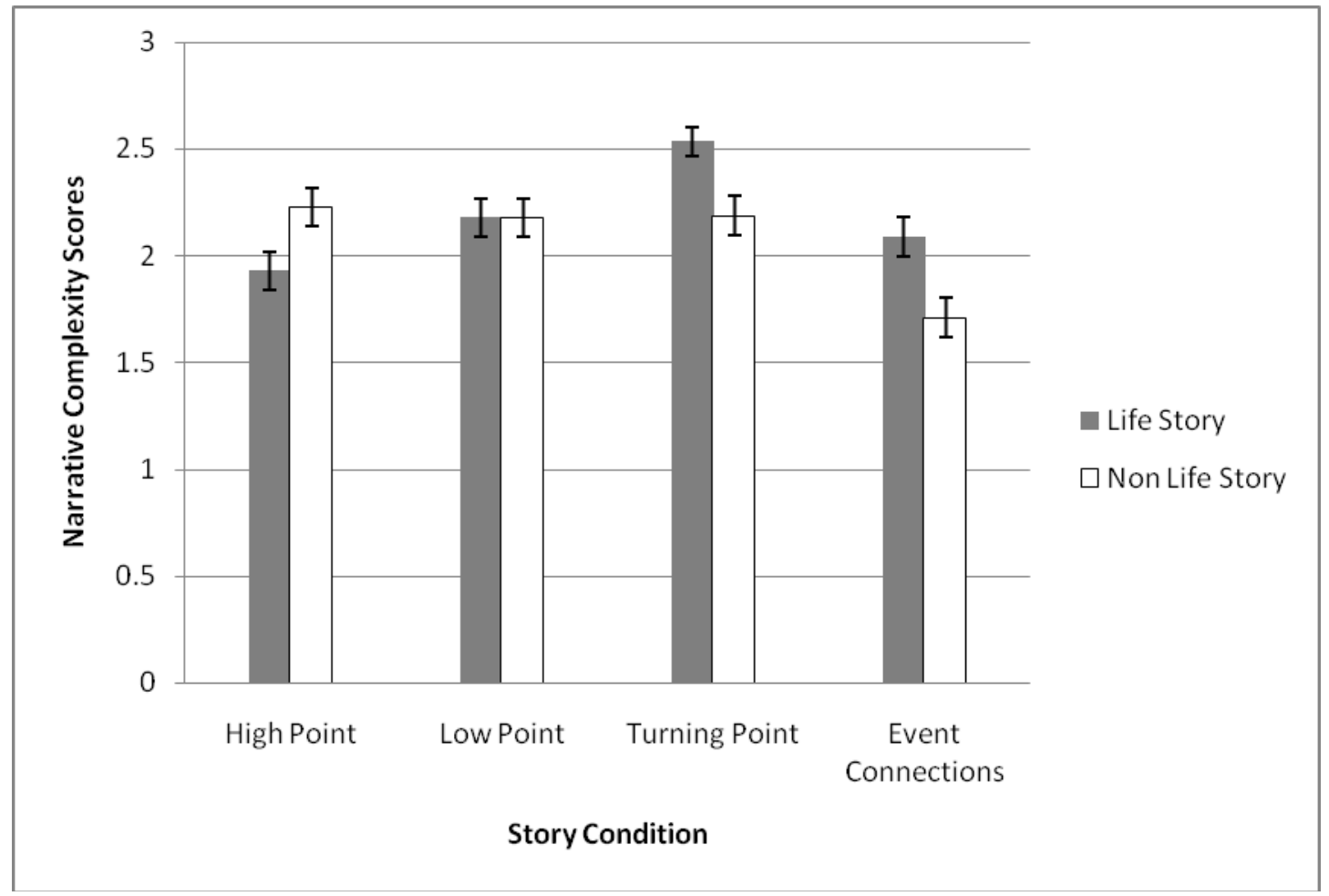

Figure 2. Means scores on Narrative Complexity Scale by narrative condition (Life Story and Non-Life Story) and story condition. Error bars represent standard errors. 


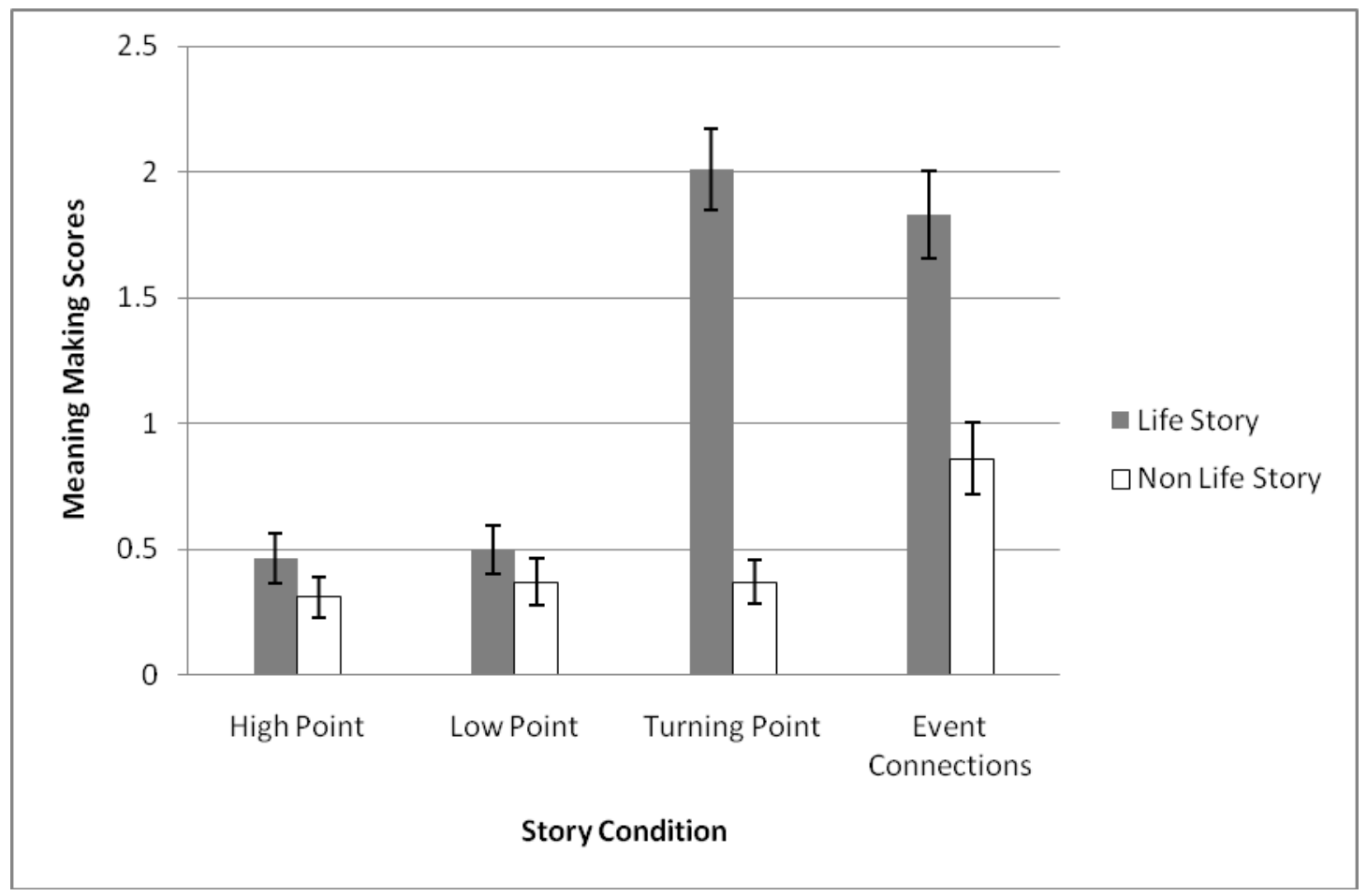

Figure 3. Means scores on Meaning Making Scale by narrative condition (Life Story and Non-Life Story) and story condition. Error bars represent standard errors. 


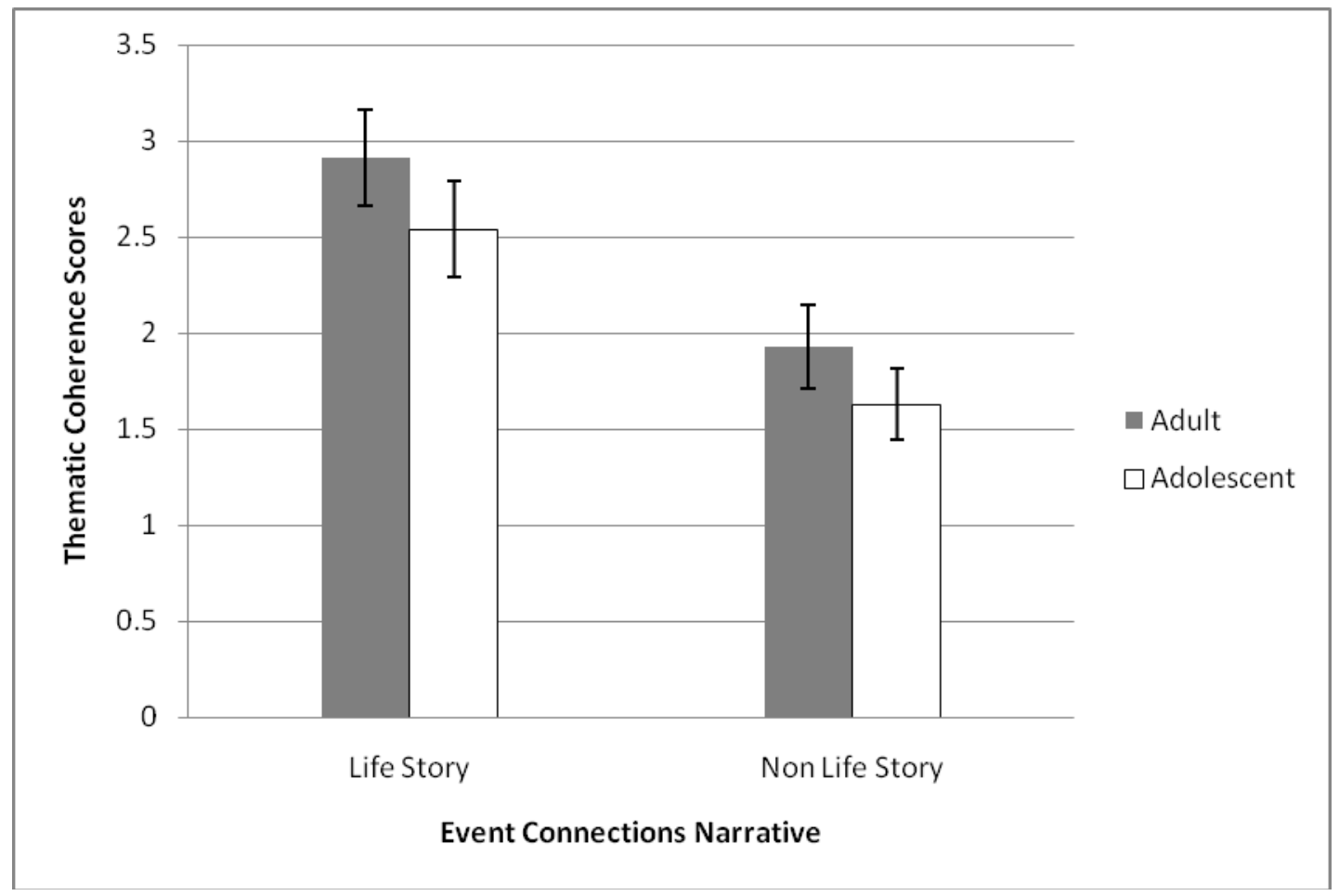

Figure 4. Mean scores on Thematic Coherence Scale by age group and narrative condition. Error bars represent standard errors. 


\section{Appendix A: Instructions to Participants}

The purpose of this exercise is to sample certain key events in your life and compare them to other, less significant events. We will be asking you to construct your own autobiography -- the story of your life as you understand it, focusing on past events. However, the autobiography will be highly selective. We will be asking you to focus on 3 particular "episodes" or "scenes" in your life story and to describe each of these in some detail. Therefore, you will not have the opportunity to tell your entire story, to relate the many different events, characters, happenings, and themes that would doubtlessly go into a full-length autobiography -- as you might do if you were writing a book about yourself. In this brief written exercise a lot of important information about you and your life will be left out. Nevertheless, we believe that focusing on only 3 episodes will provide an interesting and useful perspective from which we may view your own life story. We will also be asking you to relate 3 other memories from similar time periods as these 3 episodes. The purpose of this is to compare life memories that you think are of major significance to other, less significant memories.

People's lives vary tremendously, and people make sense of their lives in a tremendous variety of ways. We are not interested in pathology, abnormal psychology, neurosis, and psychosis. We are not trying to figure out what is wrong with you. Nor are we aiming to pass judgment on the "goodness" of your life. We won't even know who wrote it when we read it. Instead, we want to "read" your life story as if it were a book, seeing what kinds of characters, scenes, and themes you identify.

This life-story exercise is organized around the idea of critical events or episodes. An event or episode is a specific happening that occurs in a particular time and place. It is most helpful to think of such an event as constituting a specific moment in your life which stands out for some reason. Examples might be a surprise birthday party that your friends threw for you on your 18th birthday, a particular conversation with your spouse or friend in November of last year, or your reactions to learning that someone close to you died one summer day in 1986. Your last summer's vacation and a difficult week at work, by contrast, are not events because they occur over an extended period of time, even though they may be very important to you. Thus, your vacation would be more like a series of events than an event per se. We want you to concentrate on single events, rather than on a series of events or an extended period of time.

On the following pages, we will describe 3 different kinds of single events. For each one, and for the three other events, we ask that you write a description that is at least two paragraphs in length. Think about the event carefully and then include all of the following in your written description of the event:

1. When did the event occur? (How old were you?) 
2. What exactly happened in the event?

3. Who was involved in the event?

4. What were you thinking, feeling, and wanting in the event?

\section{1a. PEAK EXPERIENCE (HIGH POINT)}

Many people report occasional "peak experiences." These are generally moments or episodes in a person's life in which he or she feels a sense of great uplifting, joy, excitement, contentment, or some other highly positive emotional experience. Indeed, these experiences vary widely. Some people report them to be associated with religious or mystical experience. Others find great joy or excitement in vigorous athletics, reading a good novel, artistic expression, or in love or friendship. A peak experience may be seen as a "high point" in your life story -- a particular experience that stands out in your memory as something that is extremely positive. Please describe below in some detail a peak experience that you have experienced sometime in your life. Make sure that this is a particular and specific incident (e.g., happened at a particular time and in a particular place) rather than a general "time" or "period" in your life. Please write about exactly what happened, when it happened, who was involved, and what you were thinking and feeling.

$1 b$.

Think of the time period in which this "peak experience" happened. Now think of another memory that isn't a "peak experience," and is not related to the event you just described, but is from the same time period. Try to keep it within a year of the peak event. Make sure that this is a particular and specific incident (e.g., happened at a particular time and in a particular place) rather than a general "time" or "period" in your life. Please write about exactly what happened, when it happened, who was involved, and what you were thinking and feeling. 


\section{Appendix B: Sample Narratives}

\section{Older Sample}

\section{High Points}

The day my high school football team beat their rival for the first time in years. This was the beginning of my senior year so in the autumn. It was a half day- or we were just cutting afternoon classes and the air was really fresh and exciting. I watched my best friend cheer as I sat with several other friends-laughing and going through emotions based on the game. Being that we won one of the hotter football players decided to have a huge party at his house. It was so much fun because I had to manipulate the situation so I could go. My parents don't let me sleep over people's houses and there was no way I could just stay out until the late hours of the night. So I had my dad drop me off at Elmwood park diner where Maria's mom dropped her off thinking she would be picked up by my dad and take her home to stay with me and sleepover. I was doing the same- my parents thought I was sleeping over Maria's and just eating at the diner. It was crucial to have this happen cuz if Maria's mom saw me at her house she would know we were lying. Then we got Olga to come and get us driving someone's car I can't remember. And she took us to the party. I barely drank when it got busted by the cops. Running out the back of his house and jumping the fence I saw several kids fall into his pool's cover it was absolutely hilarious. (105)

\section{Low Points}

The experience that I recall is when my grandfather had passed away. I was about14 years old and I was a freshman in high school. Me and my grandfather were very close to each other. He wasn't sick or he didn't have any illnesses. It came out of the blue and that is why it was such a shock to everyone in my family. We were a pretty close family and were always together. When he had passed away the feelings that I felt were of sadness and angry because I was very upset that my grandfather had been taken away from me and I was angry because he was no longer there for me. I wasn't angry at anything specific, though. Just in general. My family and friends were there to help me through this time though and they helped make these feelings go away within time. (121)

\section{Turning Points}

In my school, the administration would bring in musicians to display and sample the various instruments that we could learn to play. When I was in the third grade, I attended one such assembly. At the time, I, like any other little kid, had a slight obsession and mine was Star Wars. I loved everything about it; it was my passion. During the musical assembly, the man and the woman went through all of the instruments and demonstrated each of them. Though one in particular caught my interest. The man picked up the trumpet and played the Star Wars theme. The music entered my ears and right away I knew which instrument I would learn to play. I thought that if he could do it, then I could too. Later that day, I told my parents about it and my mom suggested that I play the saxophone. Later in the week, we were able to try the instruments out ourselves and I had the easiest time with the trombone. Yet, I could not be swayed. The 
trumpet would shape my life from then on. In Junior high school, our classes were divided by team and all the band kids were in one team. Thus I had all my classes with and all my friends were from the band. In high school, I would be in the marching band and that would become my social circle. Amazingly, many of the band kids were also in the honors and AP classes and so once again all my classes were with band kids. I would play in the pit for the musicals and play in concerts. It is amazing as I look back at how much the Star Wars theme ended up shaping my life and my relationships. Music became a conduit for all that would follow socially and, even today, I participate in a musical group. (104)

\section{Event Connections}

These three events are related to each other because it defines who I am as a person. These events have made me realize that not everything can always turn out perfect. They happened to me because I was able to handle the situations. These three events are why I am the person I am today. They have taught me about loss, forgiveness, and happiness. Everyone in life experiences different things at different times and those times have taught me a lot about where I am in my life. (121)

Non-life story narratives

Over the summer, my friends and I were bored so we decided to go to Sonic. We looked up the closest one and it was in the middle of Pennsylvania, about 2.5 hours away. After long debilitation and deciding we had nothing better to do that night, me and 5 of my other friends borrowed my friends family van and went to Sonic. The whole trip there was just a lot of fun and filled with good conversations and music that we were choosing. Sonic tasted great as well but not worth the 2.5 hour trip at all. So we just hung around Sonic for a bit since it was right next to a mall but soon drove back. I felt very happy to be spending this time with my friends because soon summer would be over and none of the friends that I was with were going to any of the same schools. After getting back home, I was happy to be back and ready to sleep because spending that time in a car got me very tired. I also really hoped that I would be able to go on a trip like this again with my friends, even after we are separated by school and other things that we would be involved in for the rest of our adult lives. (106)

\section{Non-life story event connections}

The first 3 events are even less connected. The first and third one both seem to involve money, but the second doesn't. The $2^{\text {nd }}$ and $3^{\text {rd }}$ both have beautiful weather with green grass and trees involved, but the $1^{\text {st }}$ does not. They all gave me happiness though, different and varying levels of happiness, but happiness none the less. I also was able to see each in my head as vividly as ever, as if I was still there and able to look around. (113)

The other three events were minor events during the same time period that somewhat shaped the person I am today, but not as much as the other events. Since these events were during the same time period as the major events, they helped me get through the major events. I realized that if during major event I experienced sadness, then during the other event I experienced happiness. This showed the balance I had between the happy and sad events in my life. The three events were linked back to the major events that I had experienced. (115)

\section{Younger Sample}

\section{High Points}


A few years ago i had really good friend who I kind of liked a little. One day I was talking online to her and she was having a sleep over with her friends. I was talking online with her and she told me that she had to go take a shower. So she signed off. A few minutes later she signed back on. So we were talking and she told me that she liked me more than a friend. I was surprised but I was happy to. After a while her friend kept on asking me would you go out with her and I kept on saying I don't know maybe. I didn't know what to say but I was happy. (205)

\section{Low Points}

When I was in first grade my parents got divorced. It was right after my brother's bar mitzvah who is right older than me. I remember it being cold and snowy. My father didn't tell us why he wanted to get a divorce and he just left one night. I cried a lot in and out of school after my father left. A little while after my family learned the horrific story that my father was having a affair with one of his graduate students at work. I didn't understand what that meant I was only in first grade. The way my family found out was my father once told my brother that he didn't have a girlfriend. One time the brother who is just older than me was at his house and he heard someone leave an intimate message on his machine. My father told him it was someone else but my older brother figured it out. We were all upset the whole community found out and I was so embarrassed. I remember feeling sad and depressed. (202)

\section{Turning Points}

All my life I never cared what other people thought about me, because I knew that as long as i liked myself that way nobody should be able to change me. When I turned 13 I started caring what other people thought of me, I am not sure why but I guess it's just the nature of a teen to feel this way. I am a confident girl I everything I do but when someone made a comment to me about my weight everything changed. I started to exercise everyday and eat healthy. I hope that nobody ever said something to anybody like that.

\section{Event Connections}

These three major pints relate because there were all pretty major things in my life. My sister getting engaged, my first trip to Israel, and thinking that my brother could have been seriously injured are all things that really affect me in one way or another. In all three of them, there was a time where I felt really sad or emotional. At the same time, in all three of them there was a time where I felt happy or relieved. All three of these events made me really think about my life, and about how fortunate I am to have the life that I have. (255)

\section{Non-life story narratives}

In the same year that the negative experience occurred, I recall one wonderful gym class in which we kindergarteners Were given hula hoops, and if memory serves, skipping 
ropes. I chose the hula hoop and with childlike delight, rolled it like a wheel down the expanse of the gym watching spin watching it race along like a rubber tire devoid of a car and used by other youngsters. I remember a great need for the hoop to continue rolling and my joy was euphoric as for as long as it remained upright. For then, it was just me and the hoop, and the toy expanded beyond the barriers of my imagination. (234)

\section{Non-life story event connections}

They are all in the same year. (212)

Since I love camp I have many good memories from it and they are the easiest to remember that is why 2 of my short memories were stories from camp. This also occurs because my mind dwels on memories of me in different environments with different people. (216) 